\title{
LXX. Researches on the functions of plants, with a view of showing that they obey the physical laws of diffusion in the absorption and evolution of gases by their leaves and roots
}

\author{
D.P. Gardner M.D.
}

To cite this article: D.P. Gardner M.D. (1846) LXX. Researches on the functions of plants, with a view of showing that they obey the physical laws of diffusion in the absorption and evolution of gases by their leaves and roots, Philosophical Magazine Series 3, 28:189, 425-432, DOI: $10.1080 / 14786444608645453$

To link to this article: http://dx.doi.org/10.1080/14786444608645453

\section{曲 Published online: 30 Apr 2009.}

Submit your article to this journal ¿

\section{Џll Article views: 2}

Q View related articles 5 
THE

LONDON, EDINBURGH AND DUBLIN

PHILOSOPHICAL MAGAZINE

\section{A N D \\ JOURNAL OF SCIENCE.}

[THIRD SERIES.]

$J U N E 184.6$.

IXX. Researches on the Functions of Plants, with a view of showing that they obey the Physical Lawes of Diffusion in the Absorption and Evolution of Gases by their Leaves and IRoots. By D. P. Gardner, M.D., Member of the Lyceum of Natural History, \&c.*

1. I CONCEIVE a plant to be a porous system, contain1 ing an internal mixture of gases, or plant atmosphere, and lying in contact with conmon air on the one side, and with the gases dissolved in the fluid of the soil on the other. My object in the following remarks is to show that the plant atmosphere is of a fluctuating nature, and depends on the chemical action taking place; and that whatever gases are absorbed or evolved by leaves or roots, depend upon the nature of the internal atmosphere at the time. To place the evidence of these conclusions before the reader, I propose to examine the subject under five heads :-

1st. The epidermis or bounding membrane of plants is porous.

2nd. The constitution of the internal gas of plants.

3rd. The action of roots on the gases of the soil-fluid.

4th. The absorption of gases by plants is a consequence of their porosity.

5th. The action of plants on artificial atmospheres.

I. The Epidermis or Bounding Membrane of Plants is Porous.

2. The object in this place is to show, that the epidermis is not merely capable of transmitting particular gases, but that it obeys all the laws of a porous system. If this be found true for the bounding membrane, it will necessarily be true for the internal cellular structure.

* Communicated by the Author.

Phil. Mag. S. 3. Vol. 28. No. 189. June 1846. 


\section{Dr. Gardner's Researches on the Functions of Plants.}

3. Experiments were planned for the purpose of determining whether carbonic acid would penetrate into a vessel containing common air through a barrier of vegetable epidermis, and secondly, whether an inclosed mixture of gases of a theoretical composition would solicit the passage of both carbonic acid and oxygen, and at the same time evolve nitrogen.

4. A tube, five inches long and a third of an inch in bore, with a flattened and ground end, was closed by a piece of epidermis obtained from the leaf of the Madeira vine (Basella lucida). The tube was then immersed in a mercurial trough and filled to within an inch of the membrane; on suspending it by a wire it did not leak, though there was a pressure of three inches of mercury. Clear lime-water was admitted to displace the mercury, and the arrangement covered by a small bell-jar containing atmospheric air with 10 per cent. carbonic acid. In five hours the lime-water exhibited a distinct pellicle of carbonate of lime. The same result was obtained in more or less time with the epidermis of the cabbage, Alanthus alata, Chenopodium album, and several species of Sedum. Some specimens, as that from the balsam, leaked so fast as not to sustain any mercurial column, whilst others maintained four inches for thirty hours and more.

5. A similar tube was closed with epidermis, and contained an atmosphere of nitrogen 87 , oxygen 13 per cent. over mercury, and was covered with a bell-jar as above. The included volume increased during nine hours from 400 to 433 measures, and on analysis consisted of $\mathrm{N} 76, \mathrm{O} 17, \mathrm{CO}_{2} 7$ per cent. Hence the membrane comported itself as a simple porous tissue, allowing nitrogen to pass out and admitting oxygen and carbonic acid. This experiment was also repeated with the foregoing specimens of epilermis, and no absolute variation perceived.

\section{The Constitution of the Internal Gas of Plants.}

6. The observations hitherto made on the included gases of plants by Davy, Payen, Calvert and Ferrand, and others, cannot be quoted here, becanse the disturbing effects of light and other causes have not been sufficiently considered. It is not mierely the gas of a cavity which is required, but the composition of that which permeates the interior during the vigorous state of the vegetable in sun-light.

7. For the purpose of obtaining this, I transplanted in the May of 1845 a number of plants of Datura stramonium and of blue grass (Poa pratensis) into tumblers, and allowed them to grow for several weeks before use. Having completed my arrangements for analysing minutequantities of gas by a sliding- 
Dr. Gardner's Researches on the Functions of Plants. 427

rod eudiometer, I proceeded as follows:- The plants when wanted were obtained in a perfect state by immersing the tumbler in a tub of water, and removing the garden-mould by agitating the fluid; they were thus procured without the slightest mutilation. The plant was then transferred to a convenient pneumatic trough, closed from adherent air and broken under a small receiver. This was done uniformly at 11 o'clock A.M. and as quickly as possible; the gas was immediately analysed.

8. Binoxide of nitrogen was the only substance which could be used to estimate the oxygen, and if properly prepared, is, in my experience, equal to the most intricate apparatus. Thus, in twenty-five analyses of air, made as test experiments of the excellence of my measures, there was obtained a mean of 20.83 per cent. oxygen, from which there never was a variation of 0.2 per cent.; this result closely coincides with that obtained in the elaborate researches of Dumas and Boussingault, $i$. e. 21.8 per cent.

9. Six analyses of the internal gas of Datura gave a mean of $\mathrm{N} 87 \cdot 5, \mathrm{O} 12.5$ per cent. without any carbonic acid.

Four analyses of the gas from grass gave a mean of $\mathrm{N} 86 \cdot 1$, O 13.9 per cent. without carbonic acid. This result closely approximates to the measure published by Dr. Draper in the Philosophical Magazine for the gas drawn by the air-pump from grass.

The mean of all the observations is $\mathrm{N} 86.75, \mathrm{O} 13.25$ per cent.; and this I assume as the normal or plant atmosphere of the green parts at 11 to 12 o'clock A.M., during vigorous existence in the presence of bright diffused light in sunimer.

10. It is distinctly to be understood that this conditionally normal atmosphere is perpetually changing, and is true only for the time and place. In the preparatory examination of this subject, $I$ obtained measures of the internal gas consisting of $\mathrm{N} \mathrm{84} \cdot 6, \mathrm{O} 13.0, \mathrm{CO}_{2} 2 \cdot 4$ per cent, but overlooked the circumstances. Messrs. Calvert and Ferrand $\left(A n n, d e C h\right.$, \& $c_{a s}$ Aout 1844) found that carbonic acid was always present at night, and give as the composition of the gas from the hollow stems of Phytolacca decandra at night, $\mathrm{N}_{76} 4, \mathrm{O} 20^{\circ} 6, \mathrm{CO}_{\dot{2}}$ 0.3 per cent.

\section{II. The Action of Roots on the Gases of the Soil-Fluid.}

11. There are no observations on the action of roots known to me, except those of DeCandolle (Phys. Veg. t. i. p. 248), who asserts that uninjured roots exhale no gas, either in light or clarkness. Most physiologists infer, that whatever gases exist in the soil-fluid are absorbed therewith; but this is an 


\subsection{Dr. Gardner's Researches on the Functions of Plants.}

unphilosophical view, for it leaves out of consideration the capacity of the sap to absorb them and its condition as to gaseous saturation. In making experiments on the subject, it is also necessary to consider the functions of the plant.

12. On the 25th of June 1844, I commenced a series of observations to determine the action of uninjured roots of Datura and blue grass on the gas dissolved in pump-water, which accurately represents the soil-fiuid. The plants were obtained as detailed in section 7 ; they were placed in vessels resembling a bird-fountain, which were capable of being replenished with water to compensate for the evaporation of the leaves, and also of collecting any gas passing from the roots. Three sets of experiments were made: $A$, the roots and leaves were placed in darkness; $\mathrm{B}$, both portions were exposed to bright diffused light; $\mathrm{C}$, the leaves were illuminated, but the roots in darkness.

13. On the evening of the 25 th of June, two sets of plants were arranged according to these plans. The Daturas, $B$, yielded the next morning at 11 , a gas the composition of which was $\mathrm{N} 96.6, \mathrm{O} 3.4$ per cent.; these two plants were then placed in a dark cupboard for thirty-six hours and evolved no gas whatever; on again exposing them to light, they produced a mixture of $\mathrm{N} 96.2,03.8$ per cent. as the mean of six analyses. The grass plants, $B$, gave off but little gas, and only enough was collected for two measures, which yielded a mean of $\mathrm{N} 96, \mathrm{O} 4$ per cent.

The plants $\mathbf{C}$ conducted themselves in the same way as $\mathrm{B}$; the Daturas gave gas for six analyses, the mean of which was N 96.5, O 3.5 per cent.

The plants A, placed in darkness, gave no gas whatever, although they were attended to for five days.

14. We conclude that roots appear to evolve gas unequally in quantity; that the action of light on the leaves is essential to this phænomenon; and thirdly, it, the exposure of the root, does not seem to have any effect on the result. 1 do not believe that the gas is evolved from the interior of the plant, but that the roots disturb the equilibrium of the mixture in the water, so that all the carbonic acid is withdrawn and most of the oxygen, leaving behind the sparingly soluble nitrogen, which acquires the elastic condition. That this gaseous disturbance was not a mechanical effect of light and heat, I satisfied myself by observations at the time; and the results of Prof. Morren (Ann. de Chimie, \&c., Sept. 1844) show that the sun's light liberates carbonic acid and nitrogen, accumulating oxygen in the water, which is opposed to the effects here observed. 
15. The gas of the pump-water was $\mathrm{N} 48, \mathrm{O} 22, \mathrm{CO}_{2} 30$ per cent., therefore the roots absorbed carbonic acid and oxygen in the same way as a porous system containing the normal plant atmosphere, $\mathrm{N} 86.75, \mathrm{O} 13.25$ per cent.; this continued during daylight, or during the activity of the vegetable, but in darkness all the gas of the water is taken up without any selection.

\section{The Absorption of Gases by Plants is a consequence of their Porosity.}

16. We are now in possession of sufficient data to state the case. A porous system lies between two media and contains a certain mixture of gases; the gases of the three systems are

\begin{tabular}{|c|c|c|c|}
\hline Carbonic acid & $\begin{array}{c}\text { The air. } \\
0.05\end{array}$ & $\begin{array}{l}\text { The plant.gas. } \\
0.00\end{array}$ & $\begin{array}{c}\text { The water-g } \\
30.00\end{array}$ \\
\hline Oxyge & $20 \cdot 80$ & $13 \cdot 25$ & $22 \cdot 00$ \\
\hline Nitroge & - $\quad 79 \cdot 15$ & $86 \cdot 75$ & 48.00 \\
\hline & $100 \cdot 00$ & $100 \cdot 00$ & $100 \cdot 00$ \\
\hline
\end{tabular}

If the plant-gas were confined within an extremely delicate caoutchouc bag and surrounded by either atmosphere, it would soon be disturbed by penetration, nitrogen would be evolved, and carbonic acid and oxygen absorbed. The rapidity of the interchange would depend on the gas and the nature of the membrane.

17. That the action of roots on the water-gas is coincident with this theoretical view, I have attempted to show in the last division of the sulject. The experiments detailed in article 5 were also made with this object. It must be remembered that the operation of the plant atmosphere upon the gases of the soil is not direct, as in the leaves, but through the intervention of the sap, which contains a mixture of gases dependent upon those of the interior of the plant, but has a greater capacity for carbonic acid and oxygen than for nitrogen.

18. In the case of leaves, the physical theory of porosity is more strikingly made out, because the internal gas is here in contact with atmospheric air, the epidermis only lying between. The movements witnessed in the experiments of art. 5 , represent those of a vigorous plant in sun-light; carbonic acid and oxygen are absorbed and nitrogen evolved. It is not uniformly admitted that oxygen is absorbed and nitrogen evolved in plants, but an investigation of this point leaves us under the conviction that the negative is untenable. Saussure, DeCandolle, Palner, Daubeny, Draper and others have witnessed the evolution of nitrogen. The continued absorption of oxygen is confirmed by Saussure, Davy, Gough, Achard, 


\section{Dr, Gardner's Researches on the Functions of Plants.}

Scheele, Cruickshank and athers. Gough's interesting observation, that plants grown in darkness do not become green in light unless oxygen be present, is accounted for by the fact that chlorophylle is an oxidized product.

19. The movements occurring during light owe their continuance to its action. The gases absorbed are clestined to equilibrate the internal atmosphere, but cannot effect this object so long as carbon and oxygen are fixed by the plant. Hence the current becomes continuous during daylight, the oxygen and carbon being removed faster than they penetrate.

20. But during darkness the stream is arrested, carbonic acid is no longer drawn from the air, but often evolved, as observed by Ingentiousz and Saussure. Oxygen is for a time required to satisfy chemical affinities, and afterwards the internal gas resembles atmospheric air; $20^{\circ} 6$ per cent. oxygen is found, and amounts of nitrogen and carbonic acid differing with the nature of the soil-tluid, the latter gas sometimes rising to 3 per cent., when it is evolved; and at others not attaining a proportion much higher than that of the air, when it is not thrown off during night, as shown by Mr. Pepys.

21. It is the decomposition of the carbonic acid within the plant by the early sum-beams which creates the absorption from without by deranging the internal atmosphere. Carbonic acid being decomposed, a temporary excess of oxygen is produced, which causes a portion to pass outwards; but in preparing the plant for examination, any excess of this body seems to have been removed, so that it is probable that in the living organism oxygen gas is a much more important element than is usually admitted by physiologists.

\section{The Action of Plants on Artificial Atmospheres.}

22. To show beyond a doubt that the penetration of gases into plants is a physical and not vital process, we adduee the effects of artificial atmospheres. In these experiments the gases given out and absorbed are not of a definite mixture, but depend altogether on diffusion.

23. M. Marcet placed the same fungi in atmospheres of common air, oxygen, and nitrogen; and after eight to ten hours they changed 100 measures of-

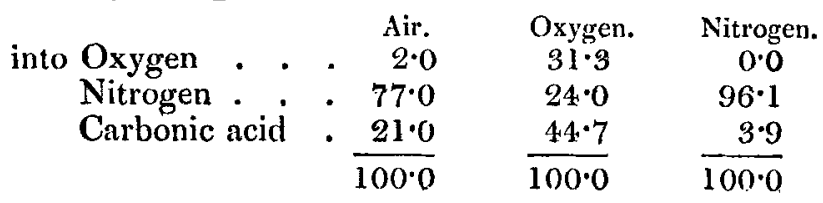

without alteration of volume (Ann, de Chiraie, \&c., t. lviii. 
p. 407). It is evident the normal atmosphere of these fungi contained an excess of nitrogen and carbonic acid. Th. de Saussure found that seeds germinating in air absorbed nitrogen, but when placed in a mixture of $\mathrm{N} 50, \mathrm{O} 50$, they no longer did so (Mem. de la Soc. de Genève, t. vi. p. 545).

24. By overlooking the laws of penetration, DeCandolle, Saussure, Ingenhousz, and Plenk are thrown into contradictory positions in their experiments on the action of the green parts of plants on artificial atmospheres. Thus DeCandolle (Phys. Veg. t. i. p. 133), "Les parties verts laissent moins de gas oxigène dans le gas hydrogène que dans le gas azote; elles ne paraissent, contre l'assertion d'Ingenhousz, absorber ni l'un ni l'autre. Il parait aussi certain, malgré l'assertion de Plenk, qu'elles n'exhalent point de gas azote, sauf dans quelques cas, par les corolles."

25 . In the summer of 1844 I tested this question by placing some specimens of the Conferva mucosa in pump-water and in carbonated water, and allowing them to act for several days on the same water, removing each day the gas generated during light; the plants were therefore subjected in their natural medium to different mixtures of gases dissolved in the fluid. The result was, that the plants in pump-water gave in six hours a gas consisting of $\mathrm{O} 73, \mathrm{~N} 27$ per cent.; in twentyfour hours, $\mathrm{O} 53, \mathrm{~N} 47$ per cent.; in forty-eight hours, $\mathrm{O} 18.6, \mathrm{~N} 81^{\circ} 4$ per cent. In carbonated water, in six hours, O 68 per cent.; in twenty-four hours, $\mathrm{O} 63$ per cent.; in forty-eight hours, $\mathrm{O} 12, \mathrm{~N} 88$ per cent.; in seventy-two hours, $\mathrm{O} 3.5, \mathrm{~N} 96.5$ per cent. And these plants continued healthy and acted as before when fresh water was added.

26. Conclusion.-From the preceding evidence $I$ infer that plants constitute a simple porous system. The advantages resulting from this philosophical view of vegetation, both in assimilating facts hitherto insulated and in criticising experimental arrangements in vegetable physiology, constitute its chief recommendation. For illustration, we adduce two general laws springing from this theory:-1st. No hypothesis nor argument can be based on the composition of the gases expired by plants without the strictest regard to the disturbing influence of light, the gases of the soil-fluid. 2ndly. No experiments on the action of plants in sun-light can be accepted in determining the functions of leaves unless 'made in atmospheric air.

27. Finally, $I$ beg to present the following summary of conclusions as fairly deducible from the preceding experiments :- 
1. The epidermis of plants, so far as experiments have been made, is porous, and permits the passage of gases according to physical laws.

2. The roots, during the existence of chemical changes in plants, absorb such gases from the soil-fluids as will indirectly satisfy the requisitions of the internal atmosphere.

3. The internal gas of plants fluctuates with the forces which operate on the plant; during the active state of the green vegetable, it resembles a mixture of nitrogen 86.75 , oxygen 13.25 per cent., but at night contains more oxygen and a proportion of carbonic acid.

4. The porosity of the entire plant is fully established by its action on artificial atmospheres.

Therefore the physical structure of plants is that of a porous system subject to the laws of diffusion of gases; and endowed with no vitality other than the power of forming cytoblasts and arranging cellules after a definite type.

\section{On the relation of Ozone to Hyponitric Acid.} By Dr. C. F. Schonbein*.

THE chemical effects produced by atmospheric air charged with hyponitric acid $\left(\mathrm{NO}_{4}\right)$ are so very like those caused by ozonized air, that some chemists are inclined to consider hyponitric acid as identical with ozone. Both decompose iodide of potassium, transform the yellow prussiate of potash into the red one, decompose sulphuretted hydrogen, colour blue the resin of guaiacum, destroy organic colouring matters, polarize negatively platinum, \&c.

In spite of the similarity of chemical properties exhibited by ozone and hyponitric acid, those substances are in many other respects so entirely different that their being identical cannot be thought of: thus ozone is produced under circumstances in which an essential constituent part of hyponitric acid is absent, namely nitrogen. The analogy existing between the chemical action of the two bodies mentioned appears however so striking, that we can hardly help suspecting some connexion to exist between them, and with the view of ascertaining that connexion I have of late made many experiments, the account of which will form the substance of this paper.

The results obtained from these researches are, in my opinion, such as to speak strongly in favour of my conjecture that there exists a compound composed of $\mathrm{NO}_{2}+\mathrm{HO}_{2}$. It

* Communicated by the Chemical Society; having been read November 3, 1845 . 